\title{
SCOPING REVIEW
}

Open Access

\section{Seroprevalence of hepatitis $E$ in adults in Brazil: a systematic review and meta- analysis}

Fátima Mitiko Tengan ${ }^{1,2^{*}}$, Gerusa M. Figueiredo ${ }^{3}$, Arielle K. S. Nunes ${ }^{2}$, Carol Manchiero², Bianca P. Dantas ${ }^{2}$, Mariana C. Magri' ${ }^{2}$, Thamiris V. G. Prata ${ }^{2}$, Marisa Nascimento ${ }^{4}$, Celso C. Mazza ${ }^{1,2}$, Edson Abdala 1,2,

Antonio A. Barone ${ }^{1,2}$ and Wanderley M. Bernardo $0^{5,6}$

\begin{abstract}
Background: Hepatitis E virus (HEV) is a member of the Hepeviridae family; it has four main genotypes and one serotype. While genotypes 1 and 2 cause epidemic hepatitis and are transmitted via water and the fecal-oral route, genotypes 3 and 4 are zoonotic. In the various seroprevalence studies of hepatitis E in Brazil, the numbers reported vary widely and are difficult to interpret. The aim of this study was to analyze existing seroprevalence studies of hepatitis $E$ in adults in Brazil.

Main text: We searched the PubMed, Latin American and Caribbean Health Sciences and Embase databases for studies published from inception to May 12, 2018 concerning infection by HEV in Brazil without time period or language restrictions. We included studies that presented data concerning hepatitis $E$ seroprevalence in adults in Brazil, had a sample size $\geq 50$ patients and whose method used for the detection of anti-HEV was standardized and commercialized. We also evaluated the quality of the articles using a list of criteria that totalized 9 items. Of the 20 studies ultimately analyzed, 10 (50\%) were from the southeast region of Brazil, 3 (15\%) were from the central-west region, 3 (15\%) were from the northern region, 2 (10\%) were from the northeast region and 2 (10\%) were from the southern region. Regarding the quality evaluation of the studies, the mean score was 5.6 (range: $4-8$ ). The estimated overall seroprevalence of HEV infection in the adult population was 6.0\% (95\% Cl: 5.0-7.0); in subgroup analyses, we observed that the prevalence of anti-HEV antibodies in blood donors was 7.0\% (95\% Cl: 5.0-8.0), whereas in the general population, it was 3.0\% (95\% Cl: 2.0-4.0).

Conclusions: The results of this systematic review indicate that there should be national investment in the prevention of hepatitis E virus infection in Brazil, including the implementation of improvements in basic sanitation and guidance regarding the appropriate handling of animal waste and the optimal cooking of vegetables, meat and their derivatives.
\end{abstract}

Keywords: Hepatitis E, Hepatitis E virus, Brazil, Prevalence, Systematic review

\footnotetext{
*Correspondence: fatima.tengan@usp.br

'Department of Infectious and Parasitic Diseases, School of Medicine, University of São Paulo (Universidade de São Paulo - USP), São Paulo, SP, Brazil

${ }^{2}$ Laboratory of Viral Medical Research in Hepatology (Laboratório de

Investigação Médica em Hepatologia por vírus - LIM-47), Clinics Hospital,

School of Medicine, USP, São Paulo, SP, Brazil

Full list of author information is available at the end of the article
}

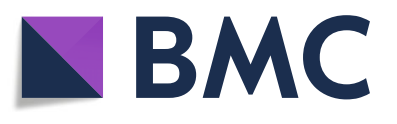

(c) The Author(s). 2019 Open Access This article is distributed under the terms of the Creative Commons Attribution 4.0 International License (http://creativecommons.org/licenses/by/4.0/), which permits unrestricted use, distribution, and reproduction in any medium, provided you give appropriate credit to the original author(s) and the source, provide a link to the Creative Commons license, and indicate if changes were made. The Creative Commons Public Domain Dedication waiver (http://creativecommons.org/publicdomain/zero/1.0/) applies to the data made available in this article, unless otherwise stated. 


\section{Multilingual abstracts}

Please see Additional file 1 for translation of the abstract into the five official working languages of the United Nations.

\section{Background}

Hepatitis E virus (HEV) is a member of the Hepeviridae family [1], which is represented by four main genotypes and one serotype. While genotypes 1 and 2 cause epidemic hepatitis and are transmitted by water and fecal-oral route, genotypes 3 and 4 are zoonotic [2]. HEV genotypes 1 and 2 are reportedly endemic in developing countries. Genotype 1 is a major cause of acute hepatitis in Asian countries, especially in India [3], while genotype 2 is prevalent in Africa and Central America. Genotype 4 is predominant in Southeast Asia. In developed countries, HEV genotypes 1, 2 and 4 are most commonly found in patients returning from international travel; however, recent cases of autochthonous genotype 4 infections have been reported in France [4, 5]. Genotype 3 is by far the most prevalent genotype and causes autochthonous infections in developed countries. Anti-HEV antibody seroprevalence is approximately $6.0 \%$ [6] in a population-based study in the USA. In Europe, blood donor studies have shown that seroprevalence of hepatitis E ranges from 3.2\% in France and 4.9\% in Switzerland to $10.0 \%$ in the United Kingdom [7-9]. However, HEV is highly endemic in specific regions, such as southern France, where the seroprevalence in blood donors reaches as high as 52.5\% [10].

In Brazil, the reported seroprevalence rates vary widely and are difficult to interpret. Reported seroprevalence in blood donors varies from $0.44 \%$ [11] to $10.0 \%$ [12]; rates from $2.0 \%$ [13] to $13.0 \%$ [14] have been reported in rural populations, and the prevalence ranges from 10.0\% [15] to $18.8 \%$ [16] in patients with comorbid diagnosis of chronic schistosomiasis. The aim of this study was therefore to systematically evaluate the divergent seroprevalence studies of hepatitis $\mathrm{E}$ in adults in Brazil.

\section{Main text}

A systematic review of published articles concerning the seroprevalence of HEV infection in adults in Brazil was carried out. Our review was conducted and reported according to the "Preferred Reporting Items for Systematic Reviews and Meta-Analyses (PRISMA) Statement," published in 2009 [17].

\section{Article search strategies}

We searched MEDLINE, Latin American and Caribbean Health Sciences (Literatura LatinoAmericana e do Caribe em Ciências da Saúde, Lilacs), and Embase databases for studies published from inception to May 12, 2018 regarding infection with HEV in Brazil without time period or language restrictions. In PubMed, we used the search terms [("Hepatitis E" OR "Hepatitis E virus" OR "Hepevirus") AND (Brazil)]. In Lilacs, we used the search terms ("Hepatite E" or "virus da Hepatite E" or "Hepevirus"). In Embase, we searched using the terms ('hepatitis e virus' AND 'brazil'); more details on the search strategies are shown in Additional file 2.

We also searched for relevant studies in the references of the selected studies and in review articles on the subject. Disagreements in the identification of relevant studies were discussed by the authors until a consensus was reached. Two researchers (GMF, MCM) independently selected the eligible studies by reading the titles and abstracts, and a list of potentially relevant studies was generated. The final articles included in the review were ultimately selected (AKSN, CM) after reading the full text of each. We contacted the study authors to request data that were not present in the published study.

\section{Study selection}

We included studies that presented data concerning hepatitis E seroprevalence in adults (age $\geq 18$ years old) in Brazil, who had a sample size greater than or equal to 50 and whose method used to detect anti-HEV antibodies was standardized and commercialized. We did not include case reports, case series, review articles, comments, studies whose participants did not live in Brazil, or studies that contained the same case series presented in other publications. Regarding the latter studies, the article with the most complete data was included in our analysis.

We used the following definition for HEV infection: the presence of both IgG and IgM anti-HEV antibodies or IgG anti-HEV as measured by enzyme immunoassay using commercial kits.

\section{Data extraction}

Two investigators (CCM, MN) collected data independently, and disagreements were resolved via discussion until reaching a consensus. The following data were collected from the articles: author name(s), year of publication, State of Brazil, population group studied, sample size, mean age, gender of the participants, number of anti-HEV antibody-positive individuals and diagnostic method for detection of anti-HEV antibodies.

\section{Quality assessment of the studies}

To evaluate the quality of included studies, we used the Joanna Briggs Institute (JBI) Critical Appraisal Checklist for Studies Reporting Prevalence Data (Additional file 3) [18]. The purpose of this appraisal is to assess the methodological quality of a study and to determine the extent to which a study has addressed the possibility of bias in its design, conduct and analysis. The instrument is 
composed of 9 items; the items were scored either positive or negative, and the importance of each item was not weighted. Higher scores (positive items) correspond to higher-quality studies for our review. We considered that the studies with scores from 0 to 3,4 to 6 and 7 to 9 presented high, moderate and low risk of bias, respectively. The quality assessment score was not used for the selection of studies for the present review. This variable (score in the quality evaluation of the study) was analyzed in meta-regression. This assessment was made independently by two researchers (BPD, TVGP), and the details of the quality assessment of the studies are shown in the Additional file 3. Disagreements during the evaluation of the quality of the studies were discussed between the researchers until a consensus was reached.

\section{Statistical analysis}

Considering the heterogeneity expected between the studies, all of the analyses were performed using the random effects model, which contemplates the variation between studies. Heterogeneity was assessed using the $I^{2}$ statistic, which describes the percentage of variation among studies that is due to heterogeneity rather than chance [19]. The following values of $I^{2}$ are considered to be evidence of mild, moderate, and high heterogeneity between studies: $25-50 \%, 51-75 \%$ and $>75 \%$, respectively. Low $I^{2}$ values suggest that the variability between estimates is compatible with random variation.

In addition, we investigated potential sources of heterogeneity by organizing groups of studies according to potentially relevant characteristics (subgroups) and by meta-regression analysis, the objective of which was to report differences in the size of the effect of the study characteristics. We performed analyses of the following subgroups: blood donor studies, the general population (which included individuals without a diagnosis of comorbidities or risk exposure) and studies using the Abbott commercial kit for the diagnosis of anti-HEV antibodies (this commercial kit was used in 13 of the 20 selected studies). By meta-regression analysis, the following factors were examined: sample size (continuous variable), year of study publication (continuous variable), and commercial kit used for detection of anti-HEV antibodies (Abbott vs. non-Abbott) and study quality (continuous variable).

To examine the publication bias, we used tests to detect asymmetry in the funnel plot proposed by Begg and Mazumdar [20] and Egger et al. [21]. Funnel plots are scatter plots generated based on the effects we want to study, which were estimated from individual studies on the horizontal axis against some measure of study size on the vertical axis. The name 'funnel plot' is based on the fact that the accuracy in estimating the effect will grow as the sample size of the included studies grow.
Estimates of the effects of small studies will therefore disperse substantially in the lower part of the graph, with the dispersion narrowing between larger studies. We also performed three sensitivity analyses; we excluded: (1) studies in which the score in the quality assessment of the studies was $\leq 5$, (2) studies in which the sample size was $\leq 100$ and (3) studies in which the sample size was $\leq 200$.

We performed all analyses using Stata version 13 software (Stat Corp LP, Texas USA) with the commands metan (for random effects meta-analysis), metareg (for meta-regression) and metabias (to test asymmetry on the funnel plot).

\section{Results}

We initially identified 197 publications in the databases (MEDLINE, Lilacs and Embase), and no other sources were obtained through manual searching (Fig. 1). After the exclusion of duplicates (66), we analyzed 131 references by reading the abstracts. A hundred and three publications were subsequently excluded, leaving 28 references selected for full text reading. After reading the full text of the 28 articles, we ultimately selected 14 for final inclusion in our review. Three publications among the 14 included studies of more than one type of population, for a grand total of 20 studies $(n=6465)$. As an example, Trinta et al. [13] studied the prevalence of anti-HEV antibodies in groups of people in the general population, pregnant women, blood donors and patients undergoing hemodialysis.

Of the 20 studies concerning the prevalence of hepatitis E virus infection in Brazil, 5 (25\%) were from the State of Rio de Janeiro, 5 (25\%) were from the State of São Paulo, 3 were from Amazonas, (15\%), 2 (10\%) were from Goiás, 2 (10\%) were from Bahia, 1 (5\%) was from Paraná, 1 (5\%) was from Santa Catarina and 1 (5\%) was from Mato Grosso (Table 1). The sample sizes ranged from 65 to $996($ mean $=323$, median $=263)$. Regarding the evaluation of the study quality, the mean score was 5.6 (median $=5.0$, range $=4-8)$. Fourteen studies scored from 4 to 7 , and 6 scored from 7 to 9 .

\section{Meta-analyses}

The estimated seroprevalence of HEV infection in the adult population of Brazil in the 20 selected studies ranged from $0.0 \%$ (95\% CI: $0.0-3.0$ ) to $10.0 \%$ (95\% CI: 7.0-15.0) (Fig. 2); the heterogeneity found between the studies was substantial $\left(I^{2}=86.7 \%\right)$. The estimated overall prevalence was $6.0 \%$ (95\% CI: 5.0-7.0).

In subgroup analyses, we observed that the prevalence of anti-HEV antibodies in blood donors was 7.0\% (95\% CI: 5.0-8.0) (Fig. 3), 3.0\% in the general population (95\% CI: 2.0-4.0) (Fig. 4) and 3.0\% in studies using the Abbott commercial kit for the diagnosis of anti-HEV antibodies (95\% CI: 2.0-4.0) (Fig. 5). 


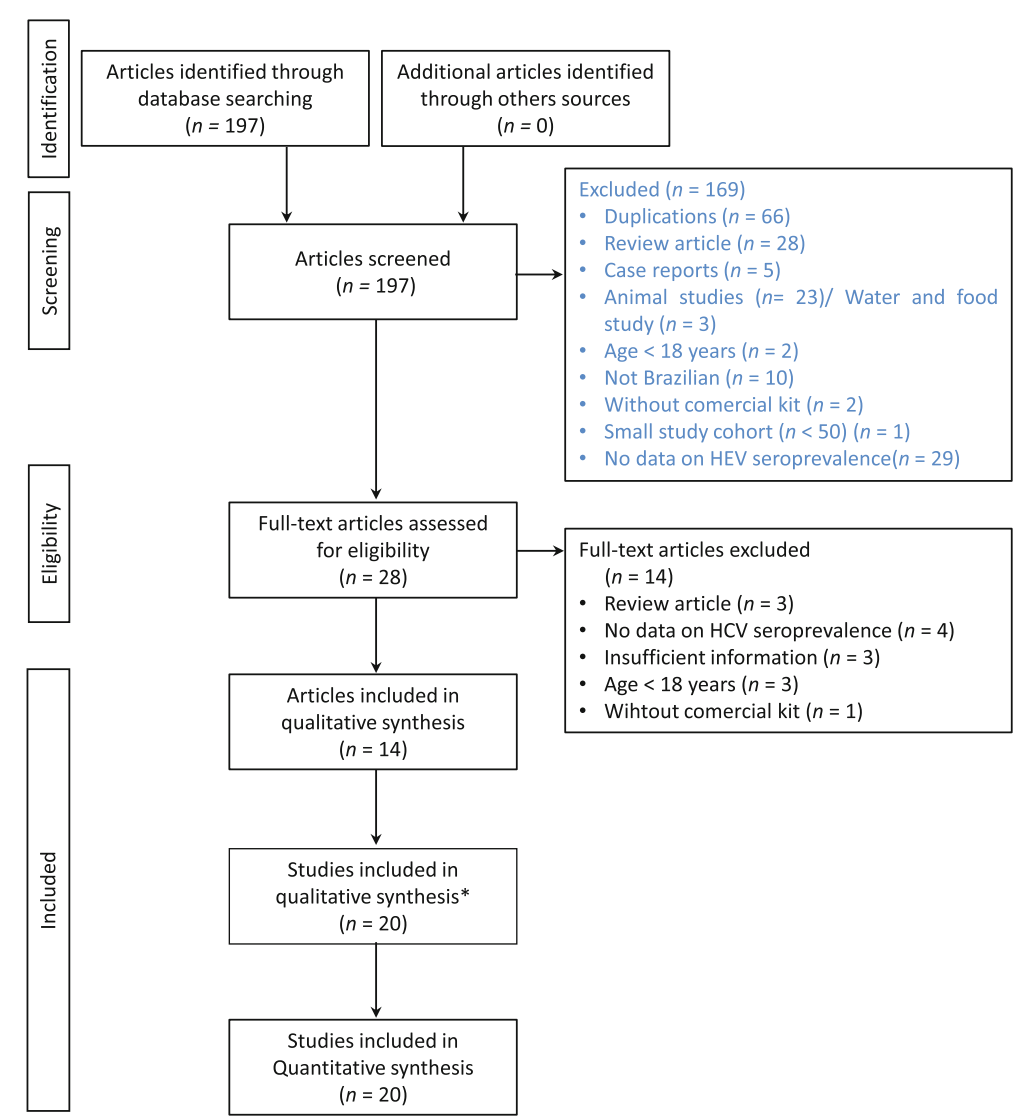

Fig. 1 Flowchart of the identification, inclusion, and exclusion criteria of the study. ${ }^{*}$ Three publications among the 14 included articles with more than one type of population, for a grand total of 20 studies

Through meta-regression analysis, we evaluated the influence of the year of study publication, the sample size, the study quality for the review objectives and the type of commercial kit used for the diagnosis of anti-HEV antibodies on the seroprevalence of hepatitis $\mathrm{E}$ (Table 2). However, only the type of commercial kit used showed a statistically significant effect.

The generated funnel plot appeared asymmetric (Additional file 4), and there was evidence of bias using the Egger method $(P=0.003)$ but not using the Begg method $(P=0.130)$ (Additional file 5).

Using only studies in which the quality assessment score was $>5$, the overall prevalence was $7.0 \%$ (95\% CI: 6.0-7.0) (Additional file 6). In studies with sample sizes $>100$, the overall prevalence was $6.0 \%$ (95\% CI: $5.0-7.0)$ (Additional file 7), and with sample sizes $>200$ was $6.0 \%$ (95\% CI: 5.0-7.0) (Additional file 8).

\section{Additional studies}

The additional selected studies were of immunosuppressed patients (i.e., living with HIV/AIDS or having undergone kidney transplantation), patients undergoing hemodialysis, patients with hepatitis $\mathrm{C}$, pregnant women and waste recyclers, as shown in Table 1 . The prevalence of anti-HEV antibodies in hemodialysis patients ranged from 0 to $6.2 \%$; in immunosuppressed people (i.e., people living with HIV/AIDS or transplanted kidneys), the variation was 2.5 to $6.5 \%$. In patients with hepatitis $\mathrm{C}$, the prevalence was $9.9 \%$, and it was $5.1 \%$ in waste recyclers. In pregnant women, the variation was 0 to $1.0 \%$.

\section{Discussion}

We systematically reviewed prevalence studies of hepatitis E conducted in Brazil and identified 20 studies from 8 Brazilian states $(n=6465)$. Our review indicated that the overall seroprevalence of hepatitis $E$ in the general adult population in Brazil was approximately $6.0 \%$ and that the heterogeneity among the studies was substantial (86.7\%). Through meta-regression analysis, we observed that of the investigated factors, only the type of commercial kit used for the detection of anti-HEV antibodies showed any statistically significant influence. In subgroup analyses, we observed that the prevalence of anti-HEV antibodies was $7.0 \%$ in blood donors, $3.0 \%$ in the general population and $3.0 \%$ in the studies that used the commercial Abbott kit to identify the presence of 
Table 1 Overall characteristics of the studies selected for the review

\begin{tabular}{|c|c|c|c|c|c|c|c|c|c|}
\hline Author & $\begin{array}{l}\text { Publication } \\
\text { year }\end{array}$ & State & $\begin{array}{l}\text { Type of patient } \\
\text { cohort }\end{array}$ & $\begin{array}{l}\text { Sample } \\
\text { size }\end{array}$ & $\begin{array}{l}\text { Positive anti- } \\
\text { HEV antibodies }\end{array}$ & $\begin{array}{l}\text { Mean } \\
\text { age }\end{array}$ & $\begin{array}{l}\text { Proportion of } \\
\text { male (\%) }\end{array}$ & $\begin{array}{l}\text { Commercial kit used } \\
\text { to diagnose anti-HEV }\end{array}$ & $\begin{array}{l}\text { Quality } \\
\text { score }\end{array}$ \\
\hline de Oliveira [41] & 2018 & Goias & $\begin{array}{l}\text { Kidney } \\
\text { transplantation }\end{array}$ & 316 & 8 & 46.4 & 55.1 & Mikrogen & 8 \\
\hline Ferreira [42] & 2018 & São Paulo & HIV & 93 & 6 & 48 & 51.6 & Mikrogen & 7 \\
\hline Bricks [43] & 2018 & São Paulo & Hepatitis C & 585 & 58 & 53.8 & 53 & Wantai & 6 \\
\hline Passos-Castilho [44] & 2017 & São Paulo & Blood donors & 500 & 49 & 38.8 & 49 & Wantai & 7 \\
\hline Passos-Castilho [12] & 2016 & Santa Catarina & Blood donors & 300 & 30 & 33.2 & 62.7 & Wantai & 7 \\
\hline Martins [45] & 2014 & Goias & Waste recyclers & 431 & 22 & 36.9 & 37.6 & Mikrogen & 7 \\
\hline Bortoliero [46] & 2006 & Parana & Blood donors & 996 & 23 & 29.9 & NA & Abbott & 8 \\
\hline Santos [47] & 2002 & Rio de Janeiro & General population & 530 & 16 & NA & NA & Abbott & 5 \\
\hline Kiesslich [11] & 2002 & Amazonas & Blood donors & 227 & 1 & NA & 81.0 & Abbott & 5 \\
\hline Kiesslich [11] & 2002 & Amazonas & Pregnant women & 100 & 0 & NA & 0 & Abbott & 5 \\
\hline Kiesslich [11] & 2002 & Amazonas & Hemodialysis & 192 & 1 & NA & 60.4 & Abbott & 5 \\
\hline Trinta [13] & 2001 & Rio de Janeiro & Blood donors & 93 & 4 & 34.6 & 100 & Abbott & 5 \\
\hline Trinta [13] & 2001 & Rio de Janeiro & Pregnant women & 304 & 3 & 23.5 & 0 & Abbott & 4 \\
\hline Trinta [13] & 2001 & Rio de Janeiro & General population & 145 & 3 & 31.3 & 52.4 & Abbott & 4 \\
\hline Trinta [13] & 2001 & Rio de Janeiro & Hemodialysis & 65 & 4 & 65.1 & 47.7 & Abbott & 4 \\
\hline Gonçales [48] & 2000 & São Paulo & Blood donors & 205 & 16 & NA & NA & Abbott & 4 \\
\hline Focaccia [38] & 1998 & São Paulo & General population & 694 & 16 & NA & NA & Abbott & 6 \\
\hline Parana [15] & 1997 & Bahia & Blood donors & 200 & 4 & 39 & 90.5 & Abbott & 5 \\
\hline Parana [15] & 1997 & Bahia & Hemodialysis & 392 & 0 & 43 & 62.3 & Abbott & 5 \\
\hline Pang [49] & 1995 & Mato Grosso & General population & 97 & 6 & NA & NA & Genelabs Inc. & 5 \\
\hline
\end{tabular}

anti-HEV antibodies. There was evidence of publication bias, but, in the sensitivity analyses, there was no significant difference in the prevalences found, indicating the robustness of the analyses performed.

Regarding countries of South America, the prevalence found in the adult population in Brazil (3.0\%) is close to that reported in Uruguay (2.8\%) [22] and Argentina (4.4\%) [23]. In blood donors, the prevalence we determined $(7.0 \%)$ is similar to that found in Chile (8.0\%) [24] and greater than that found in Uruguay (1.2\%) [22].

Commercial kits vary considerably in their performance, with a large variation in sensitivity and specificity. As emphasized by Hartl et al. [25], the anti-HEV IgG detected by the commercial Wantai kit generally produces higher estimates of seroprevalence than other commercial kits. In our analysis of studies that did not use the Wantai commercial kit, we did not find differences in the prevalence of anti-HEV antibodies as large as those described by Hartl et al. [25] (up to 8 times).

In the studies that used only the Abbott commercial kit, we determined a prevalence of $3.0 \%$, and in the analysis that included the studies that used the Wantai commercial kit, we determined a prevalence of $6.0 \%$. No definition has yet been made regarding the performance of laboratory methods capable of detecting infections that occurred in the distant past.

We believe that the difference we found in hepatitis E seroprevalence among the general population (3.0\%) and blood donors $(7.0 \%)$ was due to the difference in the performance of the commercial kits used for the detection of anti-HEV antibodies. Of the 2521 blood donors analyzed, 800 (32\%) were analyzed with the commercial Wantai kit, with the characteristics cited above. Of the two studies (blood donors) that used the Wantai commercial kit, the seroprevalence was determined to be 9.8 and $10.0 \%$. In the general population, the Wantai kit was not used for the detection of anti-HEV antibodies; the studies were done with the Abbott and Genelabs Inc. kits, which showed similar performances. The seroprevalence reported in the five studies of the general population ranged from 0.44 to $7.8 \%$ (Table 1 ). Another possibility to explain the high heterogeneity found in the studies could be the analysis of different groups, in addition to the general population and blood donors, which was done initially in our study. Due to the scarcity of studies in each of these groups (hemodialysis, immunosuppressed, hepatitis $C$, pregnant women and waste recyclers), it was not possible to perform the analysis by group of participants. 

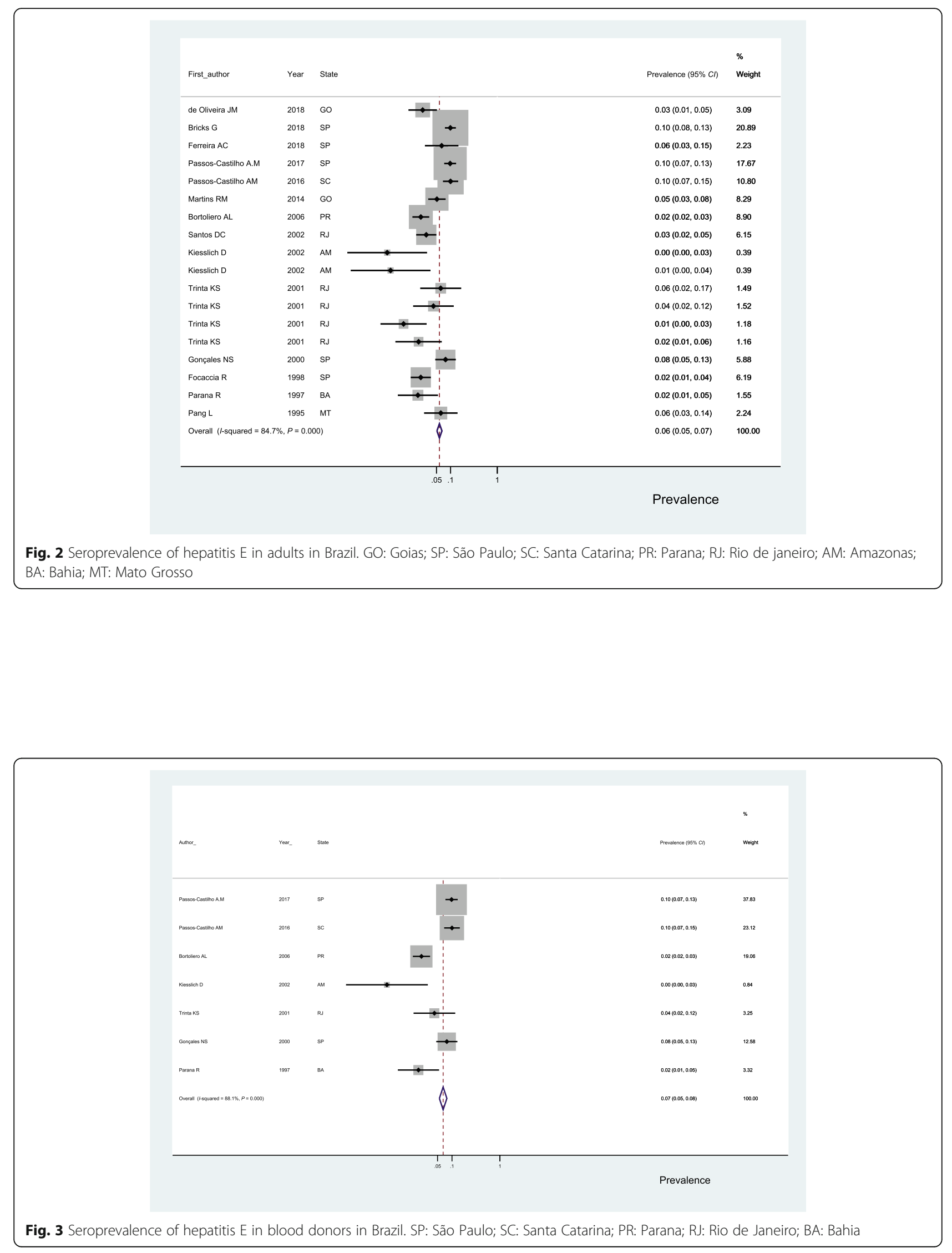


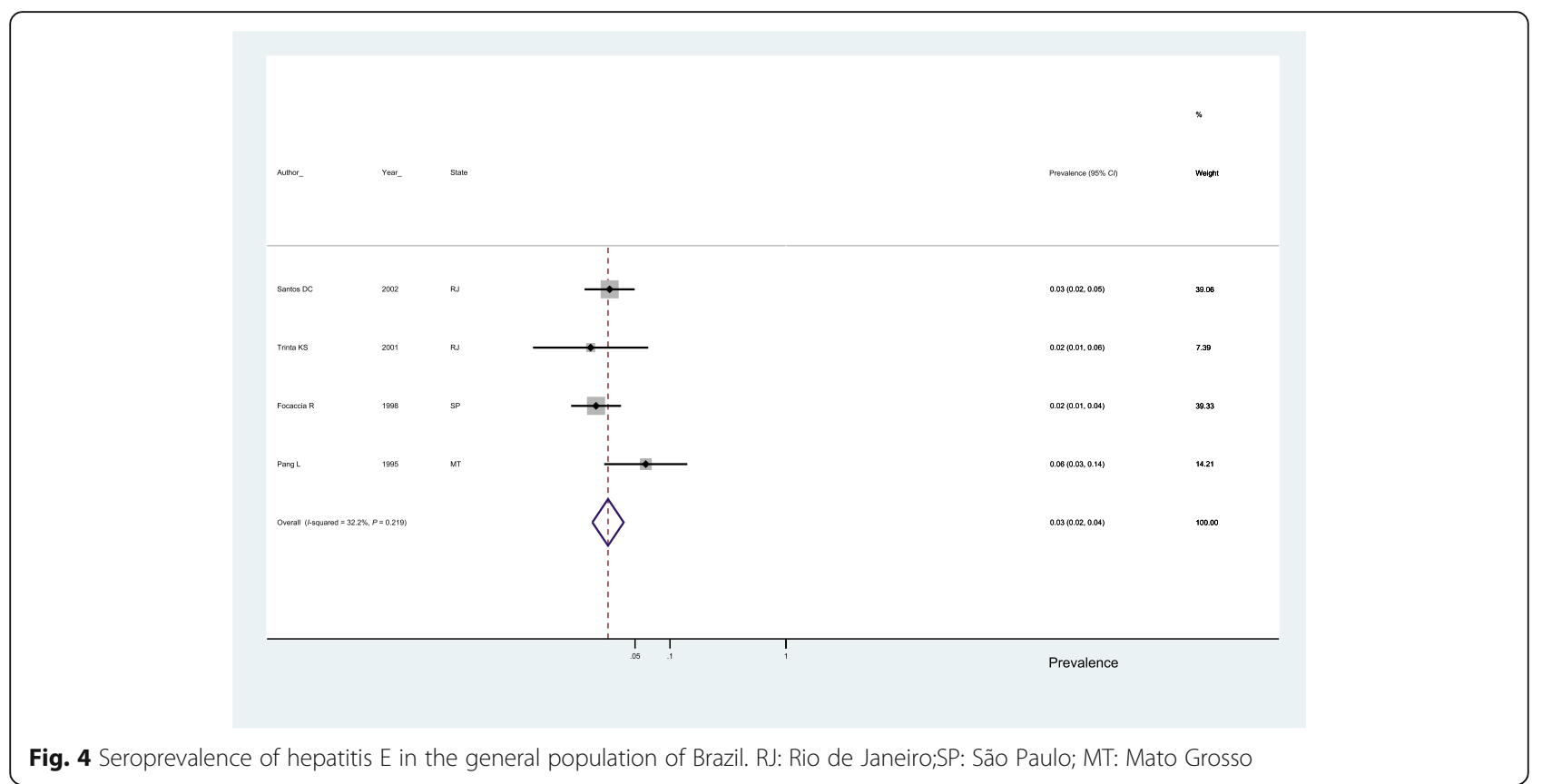

Although we have found evidence of publication bias, the sensitivity analyses appear to have shown, in our opinion, the robustness of the data obtained through the meta-analysis of the 20 selected studies. The overall prevalence confidence interval of the 20 studies (95\% CI: 5.0-7.0) overlaps with the prevalence observed in the sensitivity analyses, which sought to determine whether the exclusion of studies with smaller sample sizes or lower scores in the quality assessment of the studies would reduce the prevalence rate of anti-HEV antibodies.

Based on studies of individuals who have undergone kidney transplantation [26] and patients with previous diagnosis of non-A, non-B hepatitis [27], there are indications

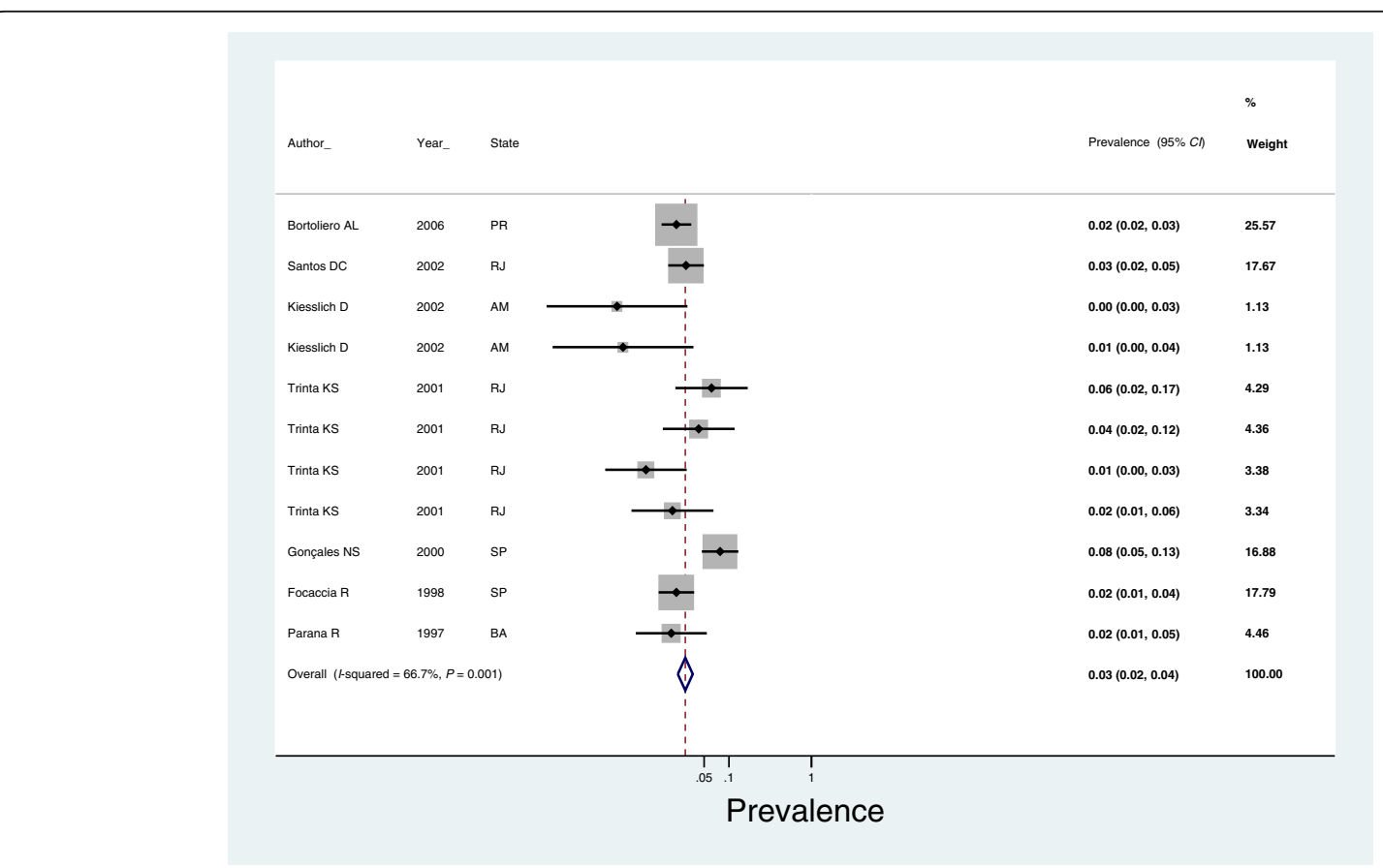

Fig. 5 Seroprevalence of hepatitis E in studies using the Abbott commercial kit for anti-HEV antibody detection. PR: Parana; RJ: Rio de Janeiro; AM: Amazonas; SP: São Paulo; BA: Bahia 
Table 2 Multivariate meta-regression analysis of the HEV seroprevalence studies in Brazil

\begin{tabular}{llll}
\hline & Meta-regression coefficient & $95 \%$ Cl & $P$-value \\
\hline Publication year & 0.024778 & $-0.0379898-0.0875458$ & 0.439 \\
Total & 0.0009374 & $-0.0009524-0.0028272$ & 0.331 \\
Quality_score & -0.3583448 & $-0.8354565-0.1187669$ & 0.141 \\
Commercial kit & 1.21865 & $0.1469347-2.290366$ & 0.026 \\
\hline
\end{tabular}

that hepatitis E virus genotype 3 is circulating among humans in Brazil.

HEV genotypes 3 and 4 are recognized for infecting humans and animals, in contrast to genotypes 1 and 2; pigs, deer and boars have been identified as reservoirs of infection $[28,29]$. In a study conducted in northeast China, the authors observed that the prevalence of anti-HEV antibodies was 31.6, 28.6 and $21.1 \%$ in individuals with frequent, infrequent and very rare contact with pigs [30]. There is also evidence that ingestion of raw or medium-raw meat and pig offal can transmit HEV [31]. In addition, HEV RNA has been found in commerciallyavailable swine livers and products derived from swine containing raw liver tissue [32], in mussels [33], in oysters [34] and in seafood [35]. It has also been found in strawberries in Canada [36] and in the supply chain of vegetables for salads in Europe [37]. It is likely that the presence of HEV in mollusks and vegetables is due to their contamination with water with animal sewage.

Our study has certain limitations. Studies of the prevalence of hepatitis $\mathrm{E}$ in the general population, as we have defined it, are not available in several Brazilian states. Except for the study by Focaccia et al. [38], we did not include another population-based study. We think it would be inconvenient to perform a more in-depth analysis of the study groups, such as those of the immunosuppressed individuals, the hemodialysis patients and the waste recyclers because the numbers of these individuals are too small to allow further inferences.

The results of this review indicate that preventive measures should be undertaken to avoid infection with the hepatitis E virus. Efficient inactivation of HEV in infected food products derived from pig livers is reportedly only achieved after a cooking time of at least $20 \mathrm{~min}$ at an internal temperature of $71^{\circ} \mathrm{C}[39,40]$. Appropriate hygienic measures must be taken when handling raw meat. In addition, pig waste must be disposed of properly, and the use of pig manure as a soil fertilizer should be regulated to reduce the risk of HEV contamination of plants and surface water.

\section{Conclusions}

The estimated overall seroprevalence of hepatitis $E$ in the Brazilian adult population was $6.0 \%$ and in subgroup analyses was $7.0 \%$ in blood donors and $3.0 \%$ in the general population, showing that HEV infection is not rare in Brazil. It is a matter of concern and alert the need for investment in the prevention of infection with HEV in Brazil that should include the improvement in basic sanitation by the government and the development and provision of guidance for the appropriate handling of waste animal and safe cooking of vegetables, meat and their derivatives. Further, it became clear that more studies are needed in different population groups and in other countries to completely understand the magnitude of the epidemiology of hepatitis E infection in Brazil.

\section{Additional files}

Additional file 1: Multilingual abstracts in the five official working languages of the United Nations. (PDF $748 \mathrm{~kb}$ )

Additional file 2: Search strategies. Search strategies used in registry databases. (DOCX $14 \mathrm{~kb}$ )

Additional file 3: A Instrument for assessment of the quality of the studies. B Assessment of the quality of the studies. Quality assessment of the selected studies. (DOCX $31 \mathrm{~kb}$ )

Additional file 4: Funnel plot analysis proposed by Begg and Mazumdar [19] to study publication bias. Funnel chart of selected studies. (PDF $47 \mathrm{~kb}$ )

Additional file 5: Tests for Publication Bias. Tests for Publication Bias. (DOCX $11 \mathrm{~kb}$ )

Additional file 6: Seroprevalence of Hepatitis $\mathrm{E}$ in studies with a quality evaluation score $>5$. (PDF $26 \mathrm{~kb}$ )

Additional file 7: Seroprevalence of Hepatitis $E$ in studies with a sample size $>100$. (PDF $26 \mathrm{~kb}$ )

Additional file 8: Seroprevalence of hepatitis $E$ in studies with a sample size $>$ 200. (PDF $26 \mathrm{~kb}$ )

\section{Abbreviations}

HEV: Hepatitis E virus; JBI: Joanna Briggs Institute; Lilacs: Literatura Latino Americana e do Caribe em Ciências da Saúde; PRISMA: Preferred Reporting Items for Systematic Reviews and Meta-Analyses

\section{Acknowledgements}

Not applicable.

Funding

No specific funding was obtained for this study.

Availability of data and materials

All data analyzed during this study are included in the published article (and its supplementary information files) and are available from the included studies, which are fully referenced.

\section{Authors' contributions}

FMT oversaw the study design, data analysis, interpretation, and drafting of the manuscript. GMF and MCM performed the searches in the databases and selected articles based on their titles and abstracts; AKSN and CM selected the studies included in the final review based on full-text analysis; CCM and 
MN extracted data from the selected articles; and BPD and TVGP assessed the quality of the studies. WMB, EA and AAB contributed to the data analysis and interpretation and oversaw critical revisions of the manuscript contents. All authors read and approved the final version of the manuscript.

\section{Ethics approval and consent to participate}

Not applicable.

\section{Consent for publication}

Not applicable.

\section{Competing interests}

The authors declare that they have no competing interests.

\section{Author details}

${ }^{1}$ Department of Infectious and Parasitic Diseases, School of Medicine, University of São Paulo (Universidade de São Paulo - USP), São Paulo, SP, Brazil. 'Laboratory of Viral Medical Research in Hepatology (Laboratório de Investigação Médica em Hepatologia por vírus - LIM-47), Clinics Hospital, School of Medicine, USP, São Paulo, SP, Brazil. ${ }^{3}$ Instituto de Medicina Tropical da Universidade de Sao Paulo, São Paulo, SP, Brazil. ${ }^{4}$ Nursing Division, Clinics Hospital, School of Medicine, USP, São Paulo, SP, Brazil. ${ }^{5}$ School of Medicine, USP, São Paulo, SP, Brazil. ' Brazilian Medical Association (AMB), São Paulo, SP, Brazil.

Received: 25 July 2018 Accepted: 25 December 2018

Published online: 16 January 2019

\section{References}

1. International Committee on Taxonomy of Viruses. 2009. https://talk. ictvonline.org/taxonomy/. Accessed 23 Sept 2018.

2. Meng XJ. Zoonotic and foodborne transmission of hepatitis E virus. Semin Liver Dis. 2013;33:41-9.

3. Kmush B, Wierzba T, Krain L, Nelson K, Labrique AB. Epidemiology of hepatitis $E$ in low- and middle-income countries of Asia and Africa. Semin Liver Dis. 2013;33:15-29.

4. Colson P, Romanet P, Moal V, Borentain P, Purgus R, Benezech A, et al. Autochthonous infections with hepatitis E virus genotype 4, France. Emerg Infect Dis. 2012;18:1361-4.

5. Jeblaoui A, Haim-Boukobza S, Marchadier E, Mokhtari C, Roque-Afonso AM Genotype 4 hepatitis e virus in France: an autochthonous infection with a more severe presentation. Clin Infect Dis. 2013;57:e122-6.

6. Teshale EH, Denniston MM, Drobeniuc J, Kamili S, Teo CG, Holmberg SD. Decline in hepatitis $\mathrm{E}$ virus antibody prevalence in the United States from 1988-1994 to 2009-2010. J Infect Dis. 2015;211:366-73.

7. Beale MA, Tettmar K, Szypulska R, Tedder RS, ljaz S. Is there evidence of recent hepatitis $E$ virus infection in English and north welsh blood donors? Vox Sang. 2011;100:340-2.

8. Boutrouille A, Bakkali-Kassimi L, Cruciere C, Pavio N. Prevalence of antihepatitis E virus antibodies in French blood donors. J Clin Microbiol. 2007; 45:2009-10.

9. Kaufmann A, Kenfak-Foguena A, Andre C, Canellini G, Burgisser P, Moradpour D, et al. Hepatitis E virus seroprevalence among blood donors in Southwest Switzerland. PLoS One. 2011;6:e21150.

10. Mansuy JM, Bendall R, Legrand-Abravanel F, Saune K, Miedouge M, Ellis V, et al. Hepatitis E virus antibodies in blood donors, France. Emerg Infect Dis. 2011;17:2309-12.

11. Kiesslich D, Rocha JE Jr, Crispim MA. Prevalence of hepatitis E virus antibodies among different groups in the Amazonian basin. Trans R Soc Trop Med Hyg. 2002;96:215.

12. Passos-Castilho AM, de Sena A, Geraldo A, Spada C, Granato CF. High prevalence of hepatitis $E$ virus antibodies among blood donors in southern Brazil. J Med Virol. 2016;88:361-4.

13. Trinta KS, Liberto MI, de Paula VS, Yoshida CF, Gaspar AM. Hepatitis E virus infection in selected Brazilian populations. Mem Inst Oswaldo Cruz. 2001;96:25-9.

14. Vitral CL, da Silva-Nunes M, Pinto MA, de Oliveira JM, Gaspar AM, Pereira RC, et al. Hepatitis A and E seroprevalence and associated risk factors: a community-based cross-sectional survey in rural Amazonia. BMC Infect Dis. $2014 ; 14: 458$.
15. Parana R, Cotrim HP, Cortey-Boennec ML, Trepo C, Lyra L. Prevalence of hepatitis $E$ virus lgG antibodies in patients from a referral unit of liver diseases in Salvador, Bahia, Brazil. Am J Trop Med Hyg. 1997;57:60-1.

16. Passos-Castilho AM, de Sena A, Domingues AL, Lopes-Neto EP, Medeiros TB, Granato CF, et al. Hepatitis E virus seroprevalence among schistosomiasis patients in Northeastern Brazil. Braz J Infect Dis. 2016;20:262-6.

17. Moher D, Liberati A, Tetzlaff J, Altman DG. Preferred reporting items for systematic reviews and meta-analyses: the PRISMA statement. J Clin Epidemiol. 2009;62:1006-12.

18. Munn Z, Moola S, Lisy K, Riitano D, Tufanaru C. Methodological guidance for systematic reviews of observational epidemiological studies reporting prevalence and incidence data. Int J Evid Based Healthc. 2015;13:147-53.

19. Higgins JP, White IR, Anzures-Cabrera J. Meta-analysis of skewed data: combining results reported on log-transformed or raw scales. Stat Med. 2008;27:6072-92.

20. Begg CB, Mazumdar M. Operating characteristics of a rank correlation test for publication bias. Biometrics. 1994;50:1088-101.

21. Egger M, Smith GD, Schneider M, Minder C. Bias in meta-analysis detected by a simple, graphical test. BMJ. 1997;315:629-34.

22. Cruells MR, Mescia G, Gaibisso R, Ramirez M, Gutierrez M, Kohen S, et al. Epidemiological study of hepatitis $A$ and $E$ viruses in different populations in Uruguay. Gastroenterol Hepatol. 1997;20:295-8.

23. Wassaf MMG, Pisano MB, Barril PA, Elbarcha OC, Pinto MA, de Oliveira JM, et al. First detection of hepatitis E virus in Central Argentina: environmental and serological survey. J Clin Virol. 2014;61:334-9.

24. Ibarra H, Riedemann S, Reinhardt G, Frieck P, Siegel F, Toledo C, et al. Prevalence of hepatitis $E$ virus antibodies in blood donors and other population groups in southern Chile. Rev Med Chil. 1997;125:275-8.

25. Hartl J, Otto B, Madden RG, Webb G, Woolson KL, Kriston L, et al. Hepatitis E Seroprevalence in Europe: A Meta-Analysis. Viruses. 2016;8:E211.

26. Passos AM, Heringer TP, Medina-Pestana JO, Ferraz ML, Granato CF. First report and molecular characterization of hepatitis $E$ virus infection in renal transplant recipients in Brazil. J Med Virol. 2013;85:615-9.

27. dos Santos DRL, Lewis-Ximenez LL, da Silva MF, de Sousa PS, Gaspar AM, Pinto MA. First report of a human autochthonous hepatitis $E$ virus infection in Brazil. J Clin Virol. 2010:47:276-9.

28. Meng XJ, Halbur PG, Shapiro MS, Govindarajan S, Bruna JD, Mushahwar IK, et al. Genetic and experimental evidence for cross-species infection by swine hepatitis E virus. J Virol. 1998;72:9714-21.

29. Tei S, Kitajima N, Takahashi K, Mishiro S. Zoonotic transmission of hepatitis $E$ virus from deer to human beings. Lancet. 2003;362:371-3.

30. Yu Y, Sun J, Liu M, Xia L, Zhao C, Harrison TJ, et al. Seroepidemiology and genetic characterization of hepatitis $E$ virus in the northeast of China. Infect Genet Evol. 2009:9:554-61.

31. Lewis HC, Wichmann O, Duizer E. Transmission routes and risk factors for autochthonous hepatitis E virus infection in Europe: a systematic review. Epidemiol Infect. 2010;138:145-66.

32. Feagins AR, Opriessnig T, Guenette DK, Halbur PG, Meng XJ. Detection and characterization of infectious hepatitis $E$ virus from commercial pig livers sold in local grocery stores in the USA. J Gen Virol. 2007;88:912-7.

33. Crossan C, Baker PJ, Craft J, Takeuchi Y, Dalton HR, Scobie L. Hepatitis E virus genotype 3 in shellfish, United Kingdom. Emerg Infect Dis. 2012; 18:2085-7.

34. Song YJ, Jeong HJ, Kim YJ, Lee SW, Lee JB, Park SY, et al. Analysis of complete genome sequences of swine hepatitis $E$ virus and possible risk factors for transmission of HEV to humans in Korea. J Med Virol. 2010;82:583-91.

35. Gao S, Li D, Zha E, Zhou T, Wang S, Yue X. Surveillance of hepatitis E virus contamination in shellfish in China. Int J Environ Res Public Health. 2015;12: 2026-36.

36. Brassard J, Gagne MJ, Genereux M, Cote C. Detection of human food-borne and zoonotic viruses on irrigated, field-grown strawberries. Appl Environ Microbiol. 2012:78:3763-6.

37. Kokkinos P, Kozyra I, Lazic S, Bouwknegt M, Rutjes S, Willems K, et al. Harmonised investigation of the occurrence of human enteric viruses in the leafy green vegetable supply chain in three European countries. Food Environ Virol. 2012:4:179-91.

38. Focaccia R, da Conceicao OJ, Sette H Jr, Sabino E, Bassit L, Nitrini DR, et al. Estimated prevalence of viral hepatitis in the general population of the municipality of Sao Paulo, measured by a serologic survey of a stratified, randomized and residence-based population. Braz J Infect Dis. 1998;2:269-84. 
39. Feagins AR, Opriessnig T, Guenette DK, Halbur PG, Meng XJ. Inactivation of infectious hepatitis $E$ virus present in commercial pig livers sold in local grocery stores in the United States. Int J Food Microbiol. 2008;123:32-7.

40. Barnaud E, Rogee S, Garry P, Rose N, Pavio N. Thermal inactivation of infectious hepatitis $E$ virus in experimentally contaminated food. Appl Environ Microbiol. 2012;78:5153-9.

41. de Oliveira J, Freitas NR, Teles SA, Bottino FO, Lemos AS, de Oliveira JM, et al. Prevalence of hepatitis $E$ virus RNA and antibodies in a cohort of kidney transplant recipients in Central Brazil. Int J Infect Dis. 2018;69:41-3.

42. Ferreira AC, Gomes-Gouvea MS, Lisboa-Neto G, Mendes-Correa MCJ, Picone CM, Salles NA, et al. Serological and molecular markers of hepatitis E virus infection in HIV-infected patients in Brazil. Arch Virol. 2018;163:43-9.

43. Bricks G, Senise JF, Pott H Jr, Grandi G, Passarini A, Caldeira DB, et al. Seroprevalence of hepatitis E virus in chronic hepatitis C in Brazil. Braz J Infect Dis. 2018:22:85-91.

44. Passos-Castilho AM, Reinaldo MR, Sena A, Granato CFH. High prevalence of hepatitis E virus antibodies in Sao Paulo, southeastern Brazil: analysis of a group of blood donors representative of the general population. Braz J Infect Dis. 2017;21:535-9.

45. Martins RM, Freitas NR, Kozlowski A, Reis NR, Lopes CL, Teles SA, et al. Seroprevalence of hepatitis $E$ antibodies in a population of recyclable waste pickers in Brazil. J Clin Virol. 2014;59:188-91.

46. Bortoliero AL, Bonametti AM, Morimoto HK, Matsuo T, Reiche EM. Seroprevalence for hepatitis E virus (HEV) infection among volunteer blood donors of the regional blood Bank of Londrina, State of Parana , Brazil. Rev Inst Med Trop Sao Paulo. 2006:48:87-92.

47. Santos DC, Souto FJ, Santos DR, Vitral CL, Gaspar AM. Seroepidemiological markers of enterically transmitted viral hepatitis $A$ and $E$ in individuals living in a community located in the North Area of Rio de Janeiro, RJ, Brazil. Mem Inst Oswaldo Cruz. 2002;97:637-40.

48. Goncales NS, Pinho JR, Moreira RC, Saraceni CP, Spina AM, Stucchi RB, et al. Hepatitis $\mathrm{E}$ virus immunoglobulin $\mathrm{G}$ antibodies in different populations in Campinas, Brazil. Clin Diagn Lab Immunol. 2000;7:813-6.

49. Pang L, Alencar FE, Cerutti C Jr, Milhous WK, Andrade AL, Oliveira R, et al. Short report: hepatitis E infection in the Brazilian Amazon. Am J Trop Med Hyg. 1995;52:347-8.

Ready to submit your research? Choose BMC and benefit from:

- fast, convenient online submission

- thorough peer review by experienced researchers in your field

- rapid publication on acceptance

- support for research data, including large and complex data types

- gold Open Access which fosters wider collaboration and increased citations

- maximum visibility for your research: over $100 \mathrm{M}$ website views per year

At $\mathrm{BMC}$, research is always in progress.

Learn more biomedcentral.com/submissions 